\title{
An egr-1 (zif268) Antisense Oligodeoxynucleotide Infused Into the Amygdala Disrupts Fear Conditioning
}

\author{
Seema Malkani, ${ }^{1}$ Karin J. Wallace, ${ }^{2}$ Melanie P. Donley, and Jeffrey B. Rosen ${ }^{3}$ \\ Program in Behavioral Neuroscience, Department of Psychology, University of Delaware, Newark, Delaware 19716, USA
}

\begin{abstract}
Studies of gene expression following fear conditioning have demonstrated that the inducible transcription factor, egr-l, is increased in the lateral nucleus of the amygdala shortly following fear conditioning. These studies suggest that $e g r-1$ and its protein product Egr-1 in the amygdala are important for learning and memory of fear. To directly test this hypothesis, an egr-1 antisense oligodeoxynucleotide (antisense-ODN) was injected bilaterally into the amygdala prior to contextual fear conditioning. The antisense-ODN reduced Egr-1 protein in the amygdala and interfered with fear conditioning. A 250-pmole dose produced an $11 \%$ decrease in Egr-1 protein and reduced long-term memory of fear as measured by freezing in a retention test $24 \mathrm{~h}$ after conditioning, but left shock-induced freezing intact. A larger 500-pmole dose produced a 25\% reduction in Egr-1 protein and significantly decreased both freezing immediately following conditioning and freezing in the retention test. A nonsense-ODN had no effect on postshock or retention test freezing. In addition, 500 pmole of antisense-ODN infused prior to the retention test in previously trained rats did not reduce freezing, indicating that antisense-ODN did not suppress conditioned fear behavior. Finally, rats infused with 500 pmole of antisense-ODN displayed unconditioned fear to a predator odor, demonstrating that unconditioned freezing was unaffected by the antisense-ODN. The data indicate that the egr- 1 antisense-ODN interferes with learning and memory processes of fear without affecting freezing behavior and suggests that the inducible transcription factor Egr-1 within the amygdala plays important functions in long-term learning and memory of fear.
\end{abstract}

The amygdala has been known for many years to be important for emotional behavior (Kluver and Bucy 1939). In the last 20 years, lesion, stimulation, drug, and recording studies have demonstrated that the lateral, basal, and central nuclei of the amygdala are critically involved in the learning and memory of fear conditioning. The lateral nucleus receives much of the sensory input from thalamic and cortical sources and sends direct and indirect (via the basal nucleus) projections to the central nucleus of the amygdala. The central nucleus generates an orchestrated fear response (Davis 1992; Rosen and Schulkin 1998; LeDoux 2000).

Although the anatomical circuitry within the amygdala involved in fear conditioning is fairly well delineated, the molecular mechanisms participating in learning and memory of fear within these nuclei are just beginning to be elucidated. Calcium influx via $\mathrm{N}$-methyl-D-aspartate (NMDA) glutamate and voltagegated calcium channels are important for initiation of cellular events that lead to changes involved in neuronal plasticity (Platenik et al. 2000). NMDA and voltage-gated calcium channel antagonists infused into the amygdala block fear conditioning and fear behavior (Miserendino et al. 1990; Campeau et al. 1992; Fanselow and Kim 1994; Maren et al. 1996; Gewirtz and Davis 1997; Fendt 2001; Lee et al. 2001; Bauer et al. 2002). Constitutive kinases and phosphorylated proteins (e.g., CREB, PKA, PKC, and MAPK/ERK) regulated by calcium act throughout the neuron to modulate excitability and transcriptional processes involved in

Present addresses: ${ }^{1}$ Neuroscience Discovery Research, Eli Lilly and Company Lilly Corporate Center, Indianapolis IN 46285; ${ }^{2}$ Wellcome Trust Centre for Human Genetics, Oxford OX3 7BN, UK. ${ }^{3}$ Corresponding author.

E-MAIL jrosen@udel.edu; FAX (302) 831-3645.

Article and publication are at http://www.learnmem.org/cgi/doi/10.1101/ Im.73104. fear conditioning (Impey et al. 1998; Schafe et al. 2000). For example, mice with deletions of the CREB or MAPK gene show deficits in long-term memory for fear (Bourtchouladze et al. 1994; Atkins et al. 1998; Selcher et al. 2001). Furthermore, blockade of protein kinase $\mathrm{A}$ and $\mathrm{C}$ in the amygdala, which phosphorylates CREB among many other phosphoproteins, disrupts long-term memory of fear conditioning (Abel et al. 1997; Goosens et al. 2000; Schafe and LeDoux 2000; Howe et al. 2002; Moita et al. 2002). Finally, overexpression of CREB in the amygdala by injection of CREB in an adenoviral vector facilitates learning and memory of fear conditioning (Josselyn et al. 2001).

In addition to signal transduction and constitutive transcription factors, inducible transcription factors act as transcriptional switches to facilitate or inhibit transcription of other genes involved in synaptic plasticity (Goelet et al. 1986; Lisman and Fallon 1999), and may play a role in long-term memory processes of fear conditioning. Recent studies have demonstrated that the inducible-transcription factor, early-growth-response-1 gene (egr-1; also called zif268, ngfi-a, krox24, and tis-8), is rapidly induced in the lateral nucleus of the amygdala following fear conditioning (Rosen et al. 1998; Hall et al. 2000; Malkani and Rosen 2000b; Ressler et al. 2002). Induction of egr-1 in the amygdala is particularly interesting because pharmacologically antagonizing NMDA receptors or inhibiting PKA or PKC was shown to interfere with long-term memory of fear conditioning and inhibit the induction of egr-1 in the lateral nucleus of the amygdala induced by fear conditioning (Malkani and Rosen 2001; S. Malkani, M.P. Donley, and J.B. Rosen, unpubl.). Furthermore, administration of the antianxiety medication, diazepam, also disrupts fear conditioning and blocks the induction of egr-1 in the lateral nucleus (Malkani and Rosen 2000a). These correlational data indirectly suggest that expression of egr-1 in the amygdala plays an important role in regulating learning and memory processes during 
fear conditioning. To directly test whether egr-1 in the amygdala is important for fear conditioning, the present study describes a number of experiments demonstrating that administration of an egr-1 antisense oligodeoxynucleotide (antisense-ODN) into the amygdala interferes with contextual fear conditioning.

\section{RESULTS}

\section{Cannula Placements}

Fifteen rats lost their cannulae before completing their experiment and were not included in the analyses. The tips of most of the cannulae in rats completing the procedures were found in the lateral or basal nuclei of the amygdala. A few were slightly ventral to the basal nucleus, in the central nucleus, or on the interface between the amygdala and the adjacent cortex (Fig. 1). Because there were no systematic differences in behavior with the various placements, behavioral data from all of these rats were used in the analyses. It also suggests that the infusions spread throughout most of the amygdala and localization to a specific nucleus could not be established.

\section{Experiment 1: egr-1 Antisense-ODN Blocked Fear Conditioning}

The effects of the egr-1 antisense-ODN given 90 min before fear conditioning are presented in Figure 2. In all groups, postshock freezing was significantly greater than was retention test freezing $\left(F_{1,44}=54.48, P \leq 0.0001\right)$. There was also a significant effect of antisense-ODN treatment $\left(F_{4,44}=11.69, P \leq 0.0001\right)$. Post-hoc analysis revealed a significant decrease in both postshock and

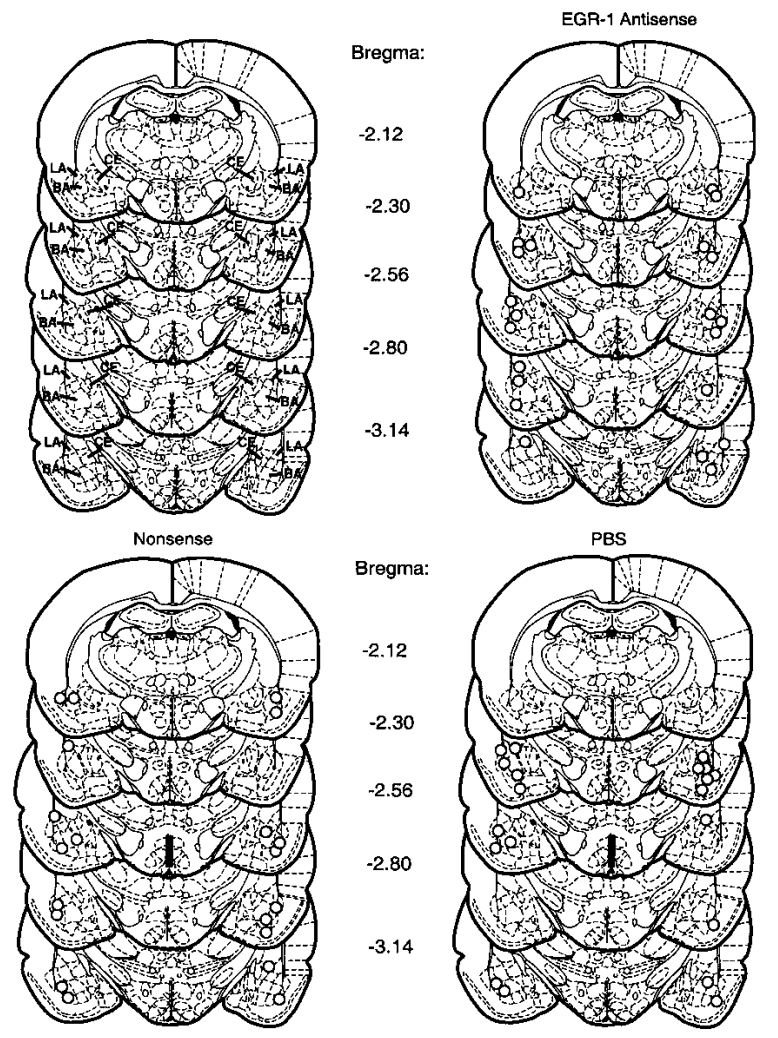

Figure 1 Cannula placements in the amygdala of rats given bilateral antisense-ODN, nonsense-ODN, and PBS infusions. Schematic diagrams of coronal brain sections at different levels posterior from Bregma are from Paxinos and Watson (1998). Upper left set of diagrams shows location of lateral (LA) basal (BA), and central (CE) nuclei of the amygdala. Each circle in the other sets of diagrams represents the tip of one cannula.

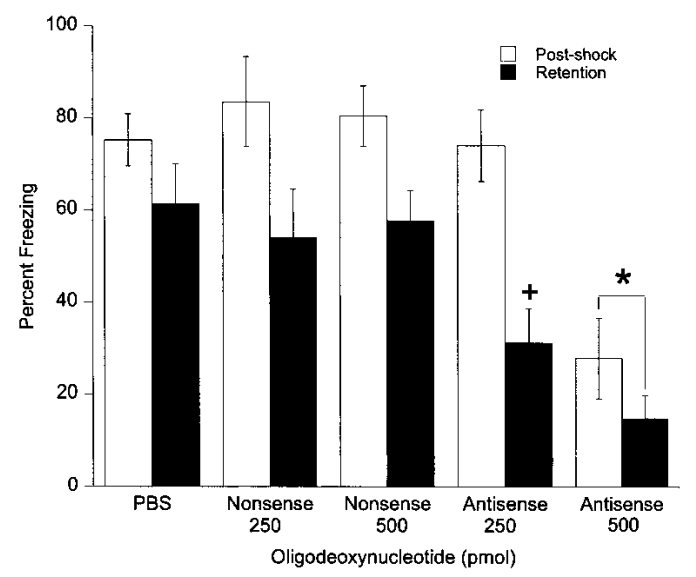

Figure 2 Effects of bilateral amygdala injections of 250 and 500 pmole egr-1 antisense-ODN and nonsense-ODN on contextual fear conditioning. Infusions were given 90 min before deliver of footshock. The 250pmole dose did not affect postshock freezing but significantly diminished freezing in the retention test compared WITH the PBS group (+). The 500-pmole dose diminished freezing in both the postshock and retention tests compared with the PBS and nonsense-ODN groups $\left({ }^{*}\right)$.

retention test freezing of the 500-pmole dose of egr-1 antisenseODN compared with all other groups $(P \leq 0.027)$. A significant interaction between the groups and time of testing $\left(F_{4,4}=2.80\right.$, $P \leq 0.037$ ) was also found. Post-hoc analysis between the 250pmole antisense-ODN and PBS groups revealed a significant effect of 250 pmole antisense-ODN on retention test freezing without an effect on postshock freezing. This suggests that 250 pmole antisense-ODN produced a specific deficit in retention of fear conditioning.

In summary, the egr-1 antisense-ODN injected into the amygdala had a dose-dependent effect on fear-induced freezing following fear conditioning. The 250-pmole dose impaired longterm memory of conditioned fear without disturbing freezing during the postshock period. The 500-pmole dose disrupted freezing for both acquisition and retention of fear conditioning.

Because the 500-pmole dose of the egr-1 antisense-ODN had a greater effect on freezing, 500 pmole of the antisense-ODN and nonsense-ODN were further tested to determine if the behavior effects were due to disruption of freezing behavior and not to learning and memory processes.

\section{No Effect of egr-1 Antisense-ODN on Shock Responsivity}

As shown in Figure 3, analysis of the rats' responses to the footshock as measured by displacement of the testing chamber during the 1-sec shock found no differences between the PBS, 500 pmole of nonsense-ODN, or 500 pmole of egr-1 antisense-ODN $\left(F_{2,29}=0.55, P=\mathrm{ns}\right)$. The data indicate that the egr-1 antisenseODN did not produce a differential immediate behavioral response to footshock.

\section{Experiment 2: Lack of an Effect of egr-1 Antisense-ODN Freezing in Retention Test}

The results of Experiment 1 suggest that egr-1 antisense-ODN given before training effectively blocked long-term memory of fear conditioning. The 500-pmole dose also blocked postshock freezing, suggesting that in addition to interfering with conditioning processes, the antisense-ODN at this dose disrupted performance of freezing behavior. Experiment 2 was designed to test whether the antisense-ODN interfered with performance of conditioned freezing behavior. Rats were trained normally without

\section{Learning \& Memory}




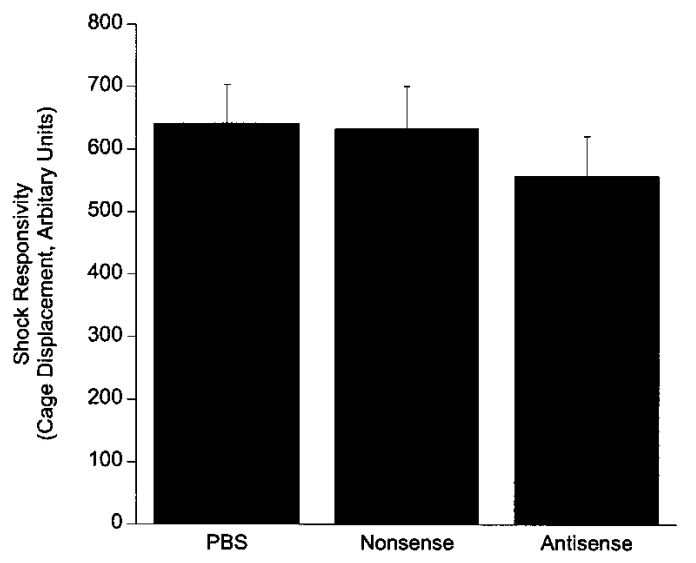

Figure 3 Responsivity to footshock during fear conditioning was not affected by 500 pmole of the antisense-ODN or nonsense-ODN.

antisense-ODN but tested for retention 90 min after receiving 500 pmole antisense-ODN or PBS infusions. As shown in Figure 4 , there were no differences between PBS and antisense-ODN freezing (ODN treatment main effect: $F_{1,12}=1.39, P=n s$ ). As in Experiment 1, rats displayed less freezing during the retention test than during the postshock period $\left(F_{1,12}=14.68, P<0.02\right)$, but this reduction of retention test freezing did not differ between the PBS and antisense-ODN groups (no ODN treatment $\times$ test time interaction: $F_{1,12}=1.40, P=n s$ ). These data demonstrate that egr-1 antisense-ODN does not disrupt the performance of the conditioned freezing response.

\section{Experiment 3: Lack of an Effect of egr-1 Antisense-ODN} on Retention Test Freezing When Given 24 h After Fear Conditioning and Before Retention Testing Reduction in freezing behavior in the retention test found in Experiment 1 could be due to a long-lasting pharmacological effect of the egr-1 antisense-ODN remaining $>24 \mathrm{~h}$ and therefore reducing freezing during retention. To test this hypothesis, rats were bilaterally administered 500 pmole egr- 1 antisense-ODN 24 $\mathrm{h}$ after fear conditioning and then tested for retention $24 \mathrm{~h}$ after the injections (the retention test was $48 \mathrm{~h}$ after conditioning). As shown in Figure 5, the egr-1 antisense-ODN had no effect on freezing in the retention test. ANOVA demonstrated that post-

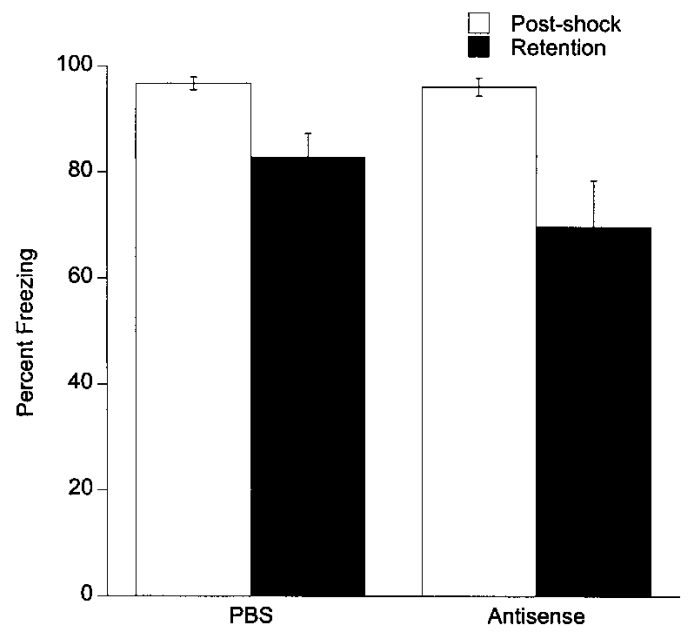

Figure 4 Lack of an effect of 500 pmole antisense-ODN on freezing when given $90 \mathrm{~min}$ before the retention test.

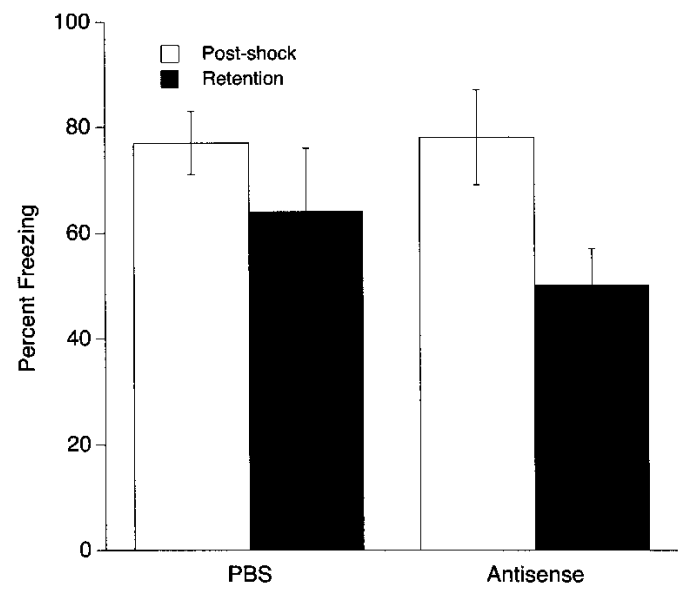

Figure 5 Lack of an effect of 500 pmole antisense-ODN on retention test freezing when administered $24 \mathrm{~h}$ after fear conditioning but $24 \mathrm{~h}$ before the retention test.

shock freezing was significantly greater than was retention test freezing $\left(F_{1,10}=10.89, P<0.008\right)$, but there was not a difference between the two groups $\left(F_{1,10}=1.12, P=n s\right)$ or a significant group by time of testing interaction $\left(F_{1,10}=1.12, P=n s\right)$. The results indicate that the decrease of retention test freezing in Experiment 1 is due to a reduction in long-term memory of contextual fear conditioning.

\section{Experiment 4: Lack of an Effect of egr-1 Antisense-ODN on Unconditioned Freezing to Predator Odor}

To further examine if egr-1 antisense-ODN interfered with freezing, an unconditioned fear test was examined by exposing rats to the predator odor trimethylthiazoline (TMT). Both the antisenseand nonsense-ODN rats displayed significantly more freezing during TMT exposure compared with freezing before TMT exposure $\left(F_{1,4}=30.22, P<0.005\right.$; Fig. 6$)$. The percentage of time spent freezing before exposure to TMT or during TMT exposure did not differ between the antisense- and nonsense-ODN groups $\left(F_{1,4}=0.42, P=n s\right)$. These results demonstrate that unconditioned freezing behavior is not disrupted by egr-1 antisense-ODN injections in the amygdala.

\section{Experiment 5: egr-1 Antisense-ODN Reduced Egr-1}

Protein Levels in the Amygdala

Both the 250- and 500-pmole doses of the antisense-ODN decreased the amount of Egr-1 protein in the amygdala, indicating

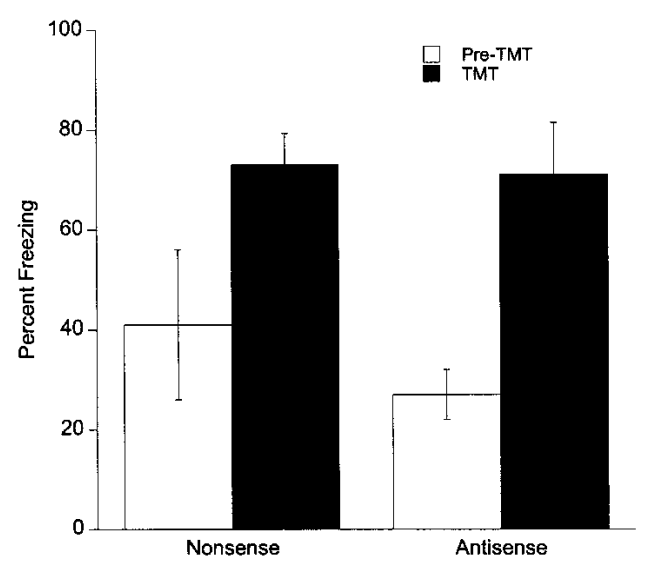

Figure 6 Lack of an effect of 500 pmole antisense-ODN on predator odor induced unconditioned freezing. 
that synthesis of Egr-1 was reduced (Fig. 7). Optical density analysis of protein extracted from tissue punches of the lateral nucleus of the amygdala revealed an $11 \%$ and $25 \%$ decrease in the levels of Egr-1 protein in rats given 250 and 500 pmole of egr-1 antisense-ODN, respectively, compared with rats receiving the same doses of nonsense-ODN. A two-factor ANOVA found a significant main effect of the antisense-ODN $\left(F_{1,47}=9.89, P<0.003\right)$ but no dose $\left(F_{1,47}=1.95, P=\right.$ ns $)$ or interaction $\left(F_{1,47}=1.39, P=n s\right)$ effect, indicating that the egr-1 antisense-ODN effectively reduced Egr-1 protein in the amygdala.

\section{DISCUSSION}

Previous correlational studies demonstrated that egr-1 mRNA expression in the lateral nucleus of the amygdala increases shortly following fear conditioning (Rosen et al. 1998; Hall et al. 2000; Malkani and Rosen 2000b; Ressler et al. 2002). Because the increase was specific for fear conditioning and not just a response to footshock (Rosen et al. 1998; Malkani and Rosen 2000b), we hypothesized that induced egr-1 mRNA expression and its protein product, Egr-1, in the lateral nucleus play a role as a transcription factor in long-term memory mechanisms of fear conditioning (Rosen et al. 1998; Malkani and Rosen 2000b). The results of the present study confirm this hypothesis. Injections of an egr-1 antisense-ODN into the amygdala, given before fear conditioning, reduced the expression of Egr-1 protein and dosedependently blocked fear conditioning as measured by fearinduced freezing. The results add to a growing body of literature suggesting that egr-1 expression plays an important role as a transcriptional switch in learning and memory processes in a variety of learning paradigms in several species (O'Donovan et al. 1999; Davis et al. 2003).
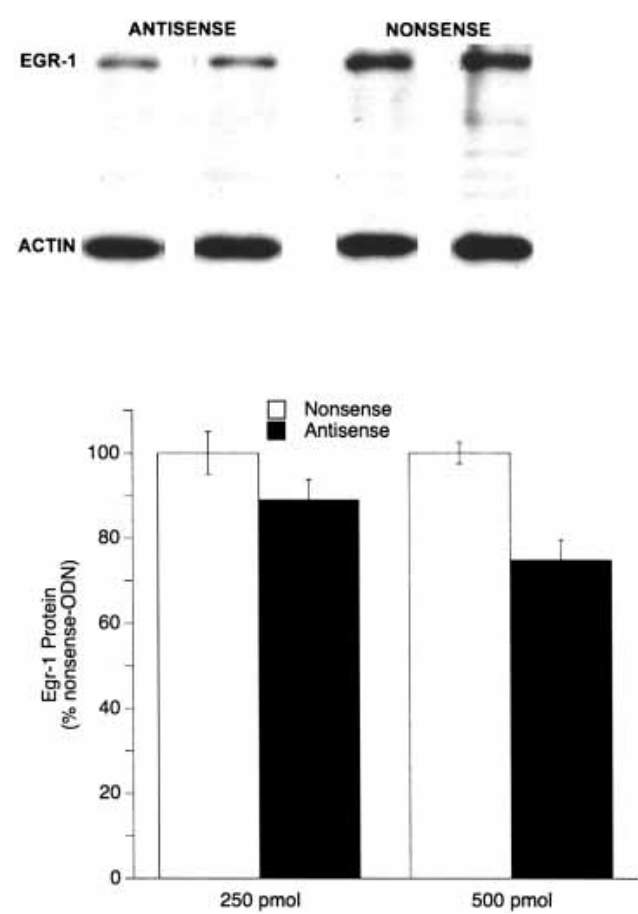

Figure 7 (Top) Four representative Western blots of Egr-1 and actin proteins from the amygdala demonstrating decreased levels of Egr-1 protein following 500 pmole of antisense-ODN. Each column of Egr-1 and actin is protein from the same animal and same lane on the blot. (Bottom) Graphic representation of decrease in Egr-1 protein in the amygdala produced by 250 and 500 pmole of egr-1 antisense-ODN. A statistically significant effect of the antisense-ODN was found $(P<0.003)$, whereas there was no effect of dose nor an ODN $x$ dose interaction.
The inclusion of a nonsense-ODN that had the same deoxynucleotides as the antisense-ODN but in a scrambled order and the use of end-capped ODNs were important variables for the present experiments. The lack of effects of the nonsense-ODN demonstrates that the disruption in fear conditioning by the egr-1 antisense-ODN was specific to the antisense sequence. As shown in the present and several other studies, end-capped phosphorothiolated antisense-ODNs can have specific effects on cellular and behavioral processes without the toxicity found with fully phosphothiolated ODNs (Hebb and Robertson 1997; Szklarczyk and Kaczmarek 1997; Chiasson et al. 1998; Kalra and Kalra 2000; Guzowski 2002; Van Oekelen et al. 2003). For egr-1 antisense-ODN, this apparently is very important because a fully phosphorothiolated egr-1 nonsense-ODN can disrupt neuronal function, as shown by electrophysiological recordings and longterm potentiation in hippocampal slices (Abraham et al. 1997).

The effects of the antisense-ODN on freezing were not due to an alteration in responsivity to footshock or an inability to freeze. More importantly, our data suggest that the effects of egr-1 antisense-ODN were due to a disruption of learning and memory processes. The lack of an effect on freezing behavior when the antisense-ODN was infused $90 \mathrm{~min}$ or $24 \mathrm{~h}$ prior to the retention test also demonstrates that the ability to freeze was not compromised. Further, antisense-ODN rats tested for unconditioned freezing to a predator odor, TMT, also froze at the same levels as nonsense-ODN rats. Freezing to a single exposure to TMT is likely a result of the properties of TMT as an unconditioned fear and aversive stimulus (Wallace and Rosen 2000; Blanchard et al. 2003). Importantly, the robust reduction in fear conditioning and retention coupled with a lack of an effect on conditioned and unconditioned freezing suggests that the effects of the egr-1 antisense-ODN are specific to learning and memory components of fear-induced freezing and not to disruption of freezing behavior per se.

The dose-response effects on both protein levels of Egr-1 and postshock freezing suggest that conditioning processes critical for long-term memory are more sensitive to interference of egr-1 than those involved in postshock freezing. A robust disruption in long-term memory, but a small $11 \%$ decrease in Egr- 1 protein produced by the 250-pmole egr-1 antisense-ODN dose indicates that only a minor perturbation in Egr-1 in the amygdala can have considerable effects on behavior. Behaviorally, the effects of the 250-pmole dose are similar to a number of other pharmacological agents (i.e., diazepam, AP-5, Rp-cAMPs, chelerythrine) that both inhibit the fear-conditioning-induced increase in egr-1 in the lateral nucleus of the amygdala and block long-term memory but not immediate postshock freezing (Malkani and Rosen 2000a; Malkani and Rosen 2001; S. Malkani, M.P. Donley, and J.B. Rosen, unpubl.). The common effects of these agents may be through a blockade of new synthesis of Egr-1. The 11\% reduction in Egr-1 protein with the 250-pmole antisense-ODN dose may be sufficient to interfere with synthesis of Egr-1 induced by fear conditioning that is involved in long-term memory formation or consolidation. In contrast, the higher 500-pmole dose of egr-1 antisense-ODN may block processes involved in freezing in the postshock period, such as forming a representation of the context and/or processing unconditioned stimulus information (Fanselow 1986, 1990; Lattal and Abel 2001; Rudy and O'Reilly 2001), by reducing constitutive Egr-1 levels in the amygdala. In this regard, constitutive or basal levels of Egr-1 are relatively robust in the lateral nucleus of the amygdala and may play a role in functions of the amygdala not explicitly connected to long-term memory formation, but do disrupt postshock freezing. It is also possible that high doses of this egr-1 antisense-ODN alter expression of other inducible transcription factors, such as c-fos (Hebb and Robertson 1997), to produce nonspecific effects that inter- 
fere with postshock freezing. Experimental methods to compare constitutive and learning induced expression of egr-1 mRNA (Guzowski 2002) and changes in levels of Egr-1 and other proteins following conditioning may further help to elucidate the temporal and functional role of $e g r-1$ in different phases of fear conditioning.

The role of egr-1 in long-term memory processes has been demonstrated in a number of learning paradigms with egr-1 knockout mice (Jones et al. 2001; Bozon et al. 2002, 2003). One interesting study found that egr-1 may be involved in reconsolidation of object recognition (Bozon et al. 2003). A recent report also found reconsolidation of contextual fear disrupted by interfering with Egr-1 protein expression in the hippocampus (Lee et al. 2004). Hippocampal infusion of the same egr-1 antisense-ODN that was used in the present study disrupted reconsolidation, but not conditioning, short-term memory or long-term retrieval of contextual fear (Lee et al. 2004). Thus, reduction of Egr-1 protein in the amygdala and hippocampus appears to have differential effects on fear conditioning but not on retrieval of fear. Although reconsolidation was not tested in the present study, expression of egr-1 in the amygdala is not induced following retrieval in our contextual fear paradigm (Rosen et al. 1998; Malkani and Rosen 2000 b) but may be induced following retrieval of cue-specific fear (Hall et al. 2001), suggesting that egr-1 in the amygdala may not be involved in reconsolidation of contextual fear as it is in the hippocampus. Direct testing of the role of amygdala egr-1 in reconsolidation of contextual and cue-specific fear is warranted and may demonstrate interesting differences in the function of egr-1 in the amygdala and hippocampus during different types of fear conditioning and reconsolidation processes.

In conclusion, blocking the synthesis of Egr-1 protein in the amygdala provides strong support for a role of egr-1 gene in fear conditioning and complements findings found in correlational studies of egr-1 expression in the amygdala (Rosen et al. 1998; Hall et al. 2000; Malkani and Rosen 2000b; Ressler et al. 2002). It will be critical to elucidate the specific role for $e g r-1$ in long-term or short-term effects of conditioning. Moreover, although egr-1 is not the only transcription factor involved in learning and memory (Davis et al. 2003), it regulates some interesting target genes and processes in a variety of biological systems. These include synapsin, acetylcholine, peptide, neuroendocrine, growth, and apoptotic genes (Thiel et al. 1994; Petersohn et al. 1995; Lee et al. 1996; Criado et al. 1997; Silverman et al. 1998; Rolli et al. 1999; Silverman and Collins 1999; Svaren et al. 2000; Thiel and Cibelli 2002; Virolle et al. 2003). Continued study of egr-1 and its role in regulation of cellular processes will contribute to a fuller understanding of the cellular and molecular nature of learning and memory.

\section{MATERIALS AND METHODS}

\section{Subjects and Surgery}

One hundred forty-one male Sprague-Dawley rats (Harlan, Indianapolis, IN) weighing 250-300 g at surgery were used in these experiments. The rats were maintained on a 12-h light/12-h dark cycle, and food and water were continuously available. All testing was done during the light cycle. The University of Delaware Institutional Animal Care and Use Committee approved all experiments.

Animals were anesthetized with a ketamine/xylazine mixture (100 mg/6.7 mg per kg, intraperitoneal). Twenty-two-gauge stainless steel guide cannulae (Plastic Products) were stereotaxically implanted bilaterally into the basolateral complex of the amygdala (coordinates were $2.6 \mathrm{~mm}$ posterior to bregma, $4.9 \mathrm{~mm}$ lateral to midline, and $7.0 \mathrm{~mm}$ ventral to the surface of the skull). Stainless steel screws and dental acrylic held the cannulae in place. A 28-gauge obturator $1 \mathrm{~mm}$ longer than the guide cannula was inserted into the guide when not in use. All rats were allowed to recover from surgery for 2 weeks. During this time, rats were brought to the laboratory and handled daily for 4 to $5 \mathrm{~min}$ each.

\section{Apparatus}

Plexiglas cylindrical chambers (8.6-cm diameter, $20 \mathrm{~cm}$ long, SRLab animal enclosure, San Diego Instruments) were used for training and testing of contextual fear conditioning. Plexiglas doors dropped into slots at each end of the cylinder kept the rat in the chamber. The rat was confined, but not restrained, and could move and turn around in the chamber, but when not turning, they faced one of the two doors. A grid floor (San Diego Instruments) consisting of seven parallel stainless steel rods measuring $4 \mathrm{~mm}$ in diameter and spaced $1.3 \mathrm{~cm}$ apart (center to center) was placed on the floor of the cylinder and attached to a scrambled shocker. The cylinder was mounted on a Plexiglas platform inside a cabinet of particleboard covered with Formica $(30 \times 30 \times 60 \mathrm{~cm}$, S-R chambers, San Diego Instruments). A 25 -W light bulb located in the roof of the cabinet was on at all times, and a fan in the cabinet provided a background noise of $70 \mathrm{~dB}$.

Responsivity to footshock could also be measured in the chambers. Each testing chamber is equipped with a piezoelectric strain gauge that transduces the cage movement generated by shock-elicited jumping, but not spontaneous movement, into a voltage proportional to displacement of the chamber. The voltage is measured every $1 \mathrm{msec}$ throughout the 1 -sec footshock. The voltage is fed into a computer, rectified, and given an average score for the entire 1-sec shock that is reflective of the shockinduced movement of the rat.

The same Plexiglas cylinders were used in the predator odor experiment. The cylinders were placed in a fumehood, instead of the Formica/particle-board chambers. The fumehood was used to evacuate a volatile predator odorant and prevent it from spreading into the experimental room. The odorant was presented to the animal by pipetting it onto a piece of Kimwipe that was taped to the inside of each door. In both context conditioning and presentation of the predator odor, the chamber was cleaned with $5 \%$ ammonium hydroxide after running each animal. In the predator odorant experiment, residual odor was also allowed to dissipate in the fumehood before another animal was brought into the experimental room and placed in the chamber.

\section{Intracranial Infusions and Scoring of Fear Behavior}

An 18-mer antisense-ODN to egr-1, an 18-mer nonsense-ODN or vehicle (PBS, pH 7.4) was infused bilaterally into the amygdala. The ODNs were purchased from Sigma-Genosys. The ODNs were phosphorothiolated on the last nucleotide at each end to protect against nuclease degradation. The sequence of the egr-1 antisense-ODN was 5'-GGTAGTTGTCCATGGTGG-3' (GenBank accession no. NM 012551, bases 348-365). The nonsense-ODN (5'GTTGGAGTCGGTGGTTCA-3') had the same nucleotide composition as the egr-1 antisense-ODN but was in an order that has no homology to any sequence in the GenBank database as confirmed by a BLAST search. Both of these ODN sequences have been used in other applications (Hebb and Robertson 1997).

For infusions, the injectors were inserted into the guide cannulae and left in place for 1 min followed by a 5-min infusion $(100 \mathrm{~nL} / \mathrm{min})$ of 250 or 500 pmole of the antisense- or nonsenseODN (all dissolved in $500 \mathrm{~nL}$ PBS), or $500 \mathrm{~nL}$ of PBS. The injectors were left in place for another minute after the infusion and then replaced with the obturator. All training and testing began 90 min after the infusions. This injection-test interval was chosen because peak efficacy for reducing EGR-1 protein levels was previously shown to be between 1 and $2 \mathrm{~h}$ after injection (Hebb and Robertson 1997).

Freezing was used as the measure of fear in all of the experiments and is characterized by cessation of movement except for breathing (Blanchard and Blanchard 1969). A rat was scored freezing or not once every $10 \mathrm{sec}$ by one or two observers blind to the experimental conditions. A percent freezing score was calcu- 
lated for each rat: [(number of freezing observations/total observations) $\times 100]$.

\section{Experiment 1: egr-1 Antisense-ODN Administered Before Contextual Fear Conditioning}

Rats were administered PBS $(n=10), 250(n=9)$ or 500 pmole antisense-ODN $(n=12)$, or $250(n=8)$ or 500 pmole nonsenseODN $(\mathrm{n}=10) 90 \mathrm{~min}$ before being placed in the testing chamber. Rats were given a 3-min preshock period to acclimate to the chamber and then received a $1-\mathrm{sec} 1.5-\mathrm{mA}$ footshock. Freezing was scored for the next $4 \mathrm{~min}$ (postshock period). In the retention test, rats were returned to the test chamber $24 \mathrm{~h}$ after conditioning and freezing was scored for $4 \mathrm{~min}$.

The responsivity to footshock was also examined in this experiment. During training, the rat's response to the 1-sec 1.5$\mathrm{mA}$ footshock was determined by chamber movement. As described in the "Apparatus" section, a piezoelectric strain gauge transduced the chamber movement generated by shockelicited jumping into a voltage proportional to the chamber displacement.

\section{Experiment 2: egr-1 Antisense-ODN Administered Before Retention Test}

To test for effects of antisense-ODN on freezing during the retention test following normal fear conditioning, rats were first given one-trial contextual fear conditioning as described in Experiment 1 except no infusions were given prior to conditioning. Approximately $22 \mathrm{~h}$ after training, PBS $(\mathrm{n}=6)$ or 500 pmole antisenseODN ( $\mathrm{n}=8)$ was injected bilaterally into the amygdala, and 90 min later, retention was tested by returning rats to the testing chamber for $4 \mathrm{~min}$ and scoring for freezing.

\section{Experiment 3: egr-1 Antisense-ODN Administered $24 \mathrm{~h}$ After Fear Conditioning and Before Retention Test}

It is possible that antisense-ODN could have pharmacological effects that last $>24 \mathrm{~h}$, and therefore, an injection administered before conditioning may not only have an influence around the time of fear conditioning but could still have a pharmacological effect on a retention test given $24 \mathrm{~h}$ after conditioning. To test for this possibility, rats were given contextual fear conditioning, and postshock freezing was scored as described above. Twenty-four hours after conditioning, rats (a time outside the window of egr-1 involvement in long-term memory consolidation) received bilateral injections of either 500 pmole egr- 1 antisense-ODN $(n=6)$ or PBS $(n=6)$. Twenty-four hours later, the rats were given a retention test and scored for freezing as described above.

\section{Experiment 4: egr-1 Antisense-ODN on Unconditioned Freezing to a Predator Odor}

To further test for the effects of the ODNs on freezing behavior, unconditioned freezing to a predator odor was examined. Rats were presented with a predator odor originally isolated from fox feces, TMT(PheroTech). TMT was previously shown to induce unconditioned freezing in rats (Wallace and Rosen 2000, 2001; Fendt et al. 2003). Rats were given bilateral infusions of 500 pmole $e g r-1$ antisense-ODN $(\mathrm{n}=3)$ or nonsense-ODN $(\mathrm{n}=3)$ into the amygdala. Ninety minutes later, they were placed in the test chambers for a 4-min pre-TMT period. Rats were then exposed to 300 nmole of TMT for 5 min. Chamber doors, each containing 150 nmole of TMT, were inserted at each end of the testing chamber to replace the nonodorous doors. Freezing behavior was scored in both the 4-min pre-TMT and 5-min TMT tests.

\section{Determination of Cannula Placements}

Following behavioral testing in Experiments 1, 2, 3, and 4, rats were anesthetized and perfused with PBS followed by formalin. The brains were removed, sectioned, and stained with cresyl violet. Cannula placements were determined by light microscopy and transcribed onto copies of the atlas of Paxinos and Watson (1998).

\section{Experiment 5: Egr-1 Protein Levels in the Amygdala Following egr-1 Antisense-ODN Administration}

To determine if the egr-1 antisense-ODN had the desired effect of reducing Egr-1 protein levels in the amygdala, rats received either $250(n=17)$ or $500(n=9)$ pmole of egr-1 antisense-ODN, or 250 $(\mathrm{n}=19)$ or $500(\mathrm{n}=6)$ pmole of nonsense-ODN 90 min before fear conditioning and then sacrificed $30 \mathrm{~min}$ after conditioning by decapitation. A 3-mm coronal brain slab containing the amygdala was cut on ice, any ventral hippocampus was retracted, and a 1-mm-diameter punch of each lateral nucleus of the amygdala was removed. The tissue was homogenized in $30 \mu \mathrm{L}$ of lysis buffer (50 mm Tris- $\mathrm{HCl}$ at $\mathrm{pH} 8.0,0.15 \mathrm{M} \mathrm{NaCl}, 1 \%$ Triton X-100, $0.25 \%$ sodium deoxycholate, protease inhibitor cocktail) and allowed to sit for $1 \mathrm{~h}$ on ice (Suneja and Potashner 1998). Protein concentrations were determined by a Bradford protein assay (Bio-Rad). Seventy-five micrograms of protein from each rat was fractionated by SDS-PAGE and then transferred to a Western blot. Polyclonal rabbit antibodies for Egr-1 (1:500, no. SC-110, Santa Cruz Biotechology), actin (1:2000, no. A2066, Sigma), and a secondary donkey anti-rabbit IgG (1:5000) supplied with the ECL Western Blotting System for chemiluminescence (no. RPN2108, Amersham Biosciences) were used to detect Egr-1 and actin on BioMax chemiluminescent-sensitive film (Kodak). Because the optical density of actin was much greater than Egr-1, chemiluminescence detection performed separately for Egr-1 and actin was used to analyze protein levels. The films were digitized, and optical density of the bands was analyzed with NIH Image (http:// rsb.info.nih.gov/nih-image/). Relative amounts of Egr-1 were calculated by standardizing the levels of Egr-1 protein to actin by dividing the optical density scores of Egr-1 protein by those of actin for each rat. For statistical analysis, a percentage of control score was derived for each rat by dividing each animal's score by the group nonsense-ODN mean and then treating the percentage of control scores to a $t$ test.

\section{ACKNOWLEDGMENTS}

This work was supported by National Science Foundation grants IBN-9904623 and IBN-0129809 awarded to J.B.R. We thank Elizabeth West for her technical assistance.

\section{REFERENCES}

Abel, T., Nguyen, P.V., Barad, M., Deuel, T.A., Kandel, E.R., and Bourtchouladze, R. 1997. Genetic demonstration of a fole for PKA in the late phase of LTP and in hippocampus-bases long-term memory. Cell 88: 615-626.

Abraham, W.C., Logan, B., Thompson, V.L., Williams, J.M., and Tate, W.P. 1997. Sequence-independent effects of phosphorothiolated oligonucleotides on synaptic transmission and excitability in the hippocampus in vivo. Neuropharmacology 36: 345-352.

Atkins, C.M., Selcher, J.C., Petraitis, J.J., Trzaskos, J.M., and Sweatt, J.D. 1998. The MAPK cascade is required for mammalian associative learning. Nat. Neurosc. 1: 602-609.

Bauer, E.P., Schafe, G.E., and LeDoux, J.E. 2002. NMDA receptors and L-type voltage-gated calcium channels contribute to long-term potentiation and different components of fear memory formation in the lateral amygdala. J. Neurosci. 22: 5239-5249.

Blanchard, D.C. and Blanchard, R.J. 1969. Crouching as an index of fear. J. Comp. Physiol. Psychol. 67: 370-375.

Blanchard, D.C., Markham, C., Yang, M., Hubbard, D., Madarang, E., and Blanchard, R.J. 2003. Failure to produce conditioning with low-dose trimethylthiazoline or cat feces as unconditioned stimuli. Behav. Neurosci. 117: 360-368.

Bourtchouladze, R., Frenguelli, B., Blendy, J., Cioffi, D., Schutz, G., and Silva, A.J. 1994. Deficient long-term memory in mice with a targeted mutation of the cAMP-responsive element-binding protein. Cell 79: $59-68$

Bozon, B., Davis, S., and Laroche, S. 2002. Regulated transcription of the 
immediate-early gene Zif268: Mechanisms and gene dosage-dependent function in synaptic plasticity and memory formation. Hippocampus 12: 570-577.

. 2003. A requirement for the immediate early gene zif268 in reconsolidation of recognition memory after retrieval. Neuron 40: $695-701$.

Campeau, S., Miserendino, M.J., and Davis, M. 1992. Intra-amygdala infusion of the $N$-methly-D-apartate receptor anatagonist AP5 blocks acquisition but not expression of fear-potentiated startle to an auditory conditioned stimulus. Behav. Neurosci. 106: 569-574.

Chiasson, B.J., Hong, M.G., and Robertson, H.A. 1998. Intra-amygdala infusion of an end-capped antisense oligodeoxynucleotide to c-fos accelerates amygdala kindling. Mol. Brain Res. 57: 248-256.

Criado, M., del Toto, E.D., Carrasco-Serrano, C., Smillie, F.I., Juiz, J.M., Viniegra, S., and Ballesta, J.J. 1997. Differential expression of $\alpha$-bungarotoxin-sensitive neuronal nicotinic receptors in adrenergic chromaffin cells: A role for transcription factor egr-1. J. Neurosci. 17: 6554-6564.

Davis, M. 1992. The role of the amygdala in conditioned fear. In The amygdala: Neurobiological aspects of emotion, memory and mental dysfunction (ed. J.P. Aggleton), pp. 255-306. Wiley-Liss, New York.

Davis, S., Bozon, B., and Laroche, S. 2003. How necessary is the activation of the immediate early gene zif268 in synaptic plasticity and learning? Behav. Brain Res. 142: 17-30.

Fanselow, M.S. 1986. Associative vs. topographical accounts of the immediate shock freezing deficit in rats: Implication for the response selection rules governing species-specific defensive reactions. Learn. Motivation 17: 16-39.

1990. Factors governing one trial contextual conditioning. Anim Learn. Behav. 18: 264-270.

Fanselow, M.S. and Kim, J.J. 1994. Acquisition of contextual Pavlovian fear conditioning is blocked by application of an NMDA receptor antagonist D.L-2-amino-5-phosphonovaleric acid to the basolateral amygdala. Behav. Neurosci. 108: 210-212.

Fendt, M. 2001. Injections of the NMDA receptor antagonist aminophosphonopentanioc acid into the lateral nucleus of the amygdala block the expression of fear-potentiated startle and freezing. J. Neurosci. 21: 4111-4115.

Fendt, M., Endres, T., and Apfelbach, R. 2003. Temporary inactivation of the bed nucleus of the stria terminalis but not of the amygdala blocks freezing induced by trimethylthiazoline, a component of fox feces. J. Neurosci. 23: 23-28.

Gewirtz, J.C. and Davis, M. 1997. Second-order fear conditioning prevented by blocking NMDA receptors in amygdala. Nature 388: $471-474$.

Goelet, P., Castellucci, V.F., Schacher, S., and Kandel, E.R. 1986. The long and the short of long-term memory: A molecular framework. Nature 322: 419-422.

Goosens, K.A., Holt, W., and Maren, S. 2000. A role for amygdaloid PKA and PKC in the acquisition of long-term conditional fear memories in rats. Behav. Brain Res. 114: 145-152.

Guzowski, J. 2002. Insights into immediate-early gene function in hippocampal memory consolidation using antisense oligonucleotide and fluorescent imaging approaches. Hippocampus 12: 86-104

Hall, J., Thomas, K.L., and Everitt, B.J. 2000. Rapid and selective induction of BDNF expression in the hippocampus during contextual learning. Nat. Neurosci. 3: 533-535.

- 2001. Cellular imaging of zif268 expression in the hippocampus and amygdala during contextual and cued fear memory retrieval: Selective activation of hippocampal CA1 neurons during the recall of contextual memories. J. Neurosci. 21: 2186-2193.

Hebb, M.O. and Robertson, H.A. 1997. End-capped antisense oligodeoxynucleotides effectively inhibit gene expression in vivo and offer a low-toxicity alternative to fully modified phosphorothioate oligodeoxynucleotides. Mol. Brain Res. 47: 223-228.

Howe, D.G., Wiley, J.C., and McKnight, G.S. 2002. Molecular and behavioral effects of a null mutation in all PKA C $\beta$ isoforms. Mol. Cell. Neurosci. 20: 515-524.

Impey, S., Smith, D.M., Obrietan, K., Donahue, R., Wade, C., and Storm, D.R. 1998. Stimulation of cAMP response element (CRE)-mediated transcription during contextual learning. Nat. Neurosci. 1: 595-601.

Jones, M.W., Errington, M.L., French, P.J., Fine, A., Bliss, T.V., Garel, S. Charnay, P., Bozon, B., Laroche, S., and Davis, S. 2001. A requirement for the immediate early gene Zif268 in the expression of late LTP and long-term memories. Nat. Neurosci. 4: 289-296.

Josselyn, S.A., Shi, C., Carlezon Jr., W.A., Neve, J.L., Nestler, E.J., and Davis. M. 2001. Long-term memory is facilitated by cAMP response element-binding protein overexpression in the amygdala. J. Neurosci. 21: 2404-2412.

Kalra, P.S. and Kalra, S.P. 2000. Use of antisense oligodeoxynucleotides to study the physiological functions of neuropeptide Y. Methods
22: $249-254$.

Kluver, H. and Bucy, P.C. 1939. Preliminary analysis of functions of the temporal lobes in monkeys. Arch. Neurol. Psych. 42: 979-1000.

Lattal, K.M. and Abel, T. 2001. An immediate-shock freezing deficit with discrete cues: A possible role for unconditioned stimulus processing mechanisms. J. Exp. Psychol. Anim. Behav. Proc. 27: 394-406.

LeDoux, J.E. 2000. Emotion circuits in the brain. Ann. Rev. Neurosci. 23: $155-184$.

Lee, S.L., Sadovsky, Y., Swirnoff, A.H., Polish, J.A., Goda, G., Gavrilina, G., and Milbrandt, J. 1996. Luteinizing hormone deficiency and female infertility in mice lacking the transcription factor NGFI-A (Egr-1). Science 273: 1219-1221.

Lee, H.J., Choi, J.S., Brown, T.H., and Kim, J.J. 2001. Amygdalar NMDA receptors are critical for the expression of multiple conditioned fear responses. J. Neurosci. 21: 4116-4124.

Lee, J.L.C., Everitt, B.J., and Thomas, K.L. 2004. Independent cellular processes for hippocampal memory consolidation and reconsolidation. Science 304: 839-843.

Lisman, J.E. and Fallon, J.R. 1999. What maintains memories? Science 283: $339-340$.

Malkani, S. and Rosen, J.B. 2000a. Differential expression of EGR-1 mRNA in the amygdala following diazepam in contextual fear conditioning. Brain Res. 860: 53-63.

. 2000b. Specific induction of immediate early growth response gene 1 (EGR-1) in the lateral nucleus of the amygdala following contextual fear conditioning in rats. Neuroscience 97: 693-702. . 2001. N-methyl-D-aspartate receptor antagonism blocks contextual fear conditioning and differentially regulates early growth response- 1 mRNA expression in the amygdala: Implications for a functional amygdaloid circuit of fear. Neuroscience 102: $853-861$.

Maren, S., Aharonov, G., Stote, D.L., and Fanselow, M.S. 1996. $N$-methyl-D-aspartate receptors in the basolateral amygdala are required for both acquisition and expression of conditional fear in rats. Behav. Neurosci. 110: $1365-1374$.

Miserendino, M.J.D., Sananes, C.B., Melia, K.R., and Davis, M. 1990. Blocking of acquisition but not expression of conditioned fear-potentiated startle by NMDA antagonists in the amygdala. Nature 345: 716-718.

Moita, M.A., Lamprecht, R., Nader, K., and LeDoux, J.E. 2002. A-kinase anchoring proteins in amygdala are involved in auditory fear memory. Nat. Neurosci. 5: 837-838.

O'Donovan, K.J., Tourtellotte, W.G., Millbrandt, J., and Baraban, J.M. 1999. The EGR family of transcription-regulatory factors: Progress at the interface of molecular and systems neuroscience. Trends Neurosci. 22: $167-173$.

Paxinos, G. and Watson, CA. 1998. The rat brain in stereotaxic coordinates. Adacemic Press, San Diego, CA.

Petersohn, D., Schoch, S., Brinkmann, D.R., and Thiel, G. 1995. The human synapsin II gene promotor: Possible role for the transcription factor zif268/egr-1, polyoma enhancer activator 3, and AP2. J. Biol. Chem. 270: 24361-24369.

Platenik, J., Kuramoto, N., and Yoneda, Y. 2000. Molecular mechanisms associated with long-term consolidation of the NMDA signals. Life Sci. 67: 335-364.

Ressler, K.J., Paschall, G., Zhou, X.L., and Davis, M. 2002. Regulation of synaptic plasticity genes during consolidation of fear conditioning. $J$. Neurosci. 22: 7892-7902.

Rolli, M., Kotlyarov, A., Sakamoto, K.M., Gaestel, M., and Nieninger, A. 1999. Stress-induced stimulation of early growth response gene- 1 by p38/stress-activated protein kinase 2 is mediated by a cAMP-responsive promotor element in a MAPKAP kinase-2 independent manner. J. Biol. Chem. 274: 19559-19564.

Rosen, J.B. and Schulkin, J. 1998. From normal fear to pathological anxiety. Psychol. Rev. 105: 325-350.

Rosen, J.B., Fanselow, M.S., Young, S.L., Sitcoske, M., and Maren, S. 1998. Immediate-early gene expression in the amygdala following footshock stress and contextual fear conditioning. Brain Res. 796: $132-142$

Rudy, J.W. and O'Reilly, R.C. 2001. Conjunctive representations, the hippocampus and contextual fear conditioning. Cogn. Affective Behav. Neurosci. 1: 66-82.

Schafe, G.E. and LeDoux, J.E. 2000. Memory consolidation of auditory Pavlovian fear conditioning requires protein synthesis and protein kinase A in the amygdala. J. Neurosci. 20: 1-5.

Schafe, G.E., Atkins, C.M., Swank, M.W., Bauer, E.P., Sweatt, J.D., and LeDoux, J.E. 2000. Activation of ERK/MAP kinase in the amygdala is required for memory consolidation of Pavlovian fear conditioning. $J$. Neurosci. 20: 8177-8187.

Selcher, J.C., Nekrasova, T., Paylor, R., Landreth, G.E., and Sweatt, J.D. 2001. Mice lacking the ERK1 isoform of MAP kinase are unimpaired in emotional learning. Learn. Mem. 8: 11-19. 
Malkani et al.

Silverman, E.S. and Collins, T. 1999. Pathways of egr-1 mediated gene transcription in vascular biology. Am. J. Pathol. 154: 665-670.

Silverman, E.S., Du, J., Williams, A.J., Wadgaonkar, R., Drazen, J.M., and Collins, T. 1998. cAMP-response-element-binding-protein-binding protein (CBP) and p300 are transcriptional co-activators of early growth response factor-1 (Egr-1). Biochem. J. 336(Pt 1): 183-189.

Suneja, S. and Potashner, S. 1998. Quantification of a neurotrophin receptor from submilligram quantities of brain tissue using Western blotting. Brain Res. Protocols 3: 88-93.

Svaren, J., Ehrig, T., Abdulkadir, S.A., Ehrengruber, M.U., Watson, M.A and Milbrandt, J. 2000. EGR1 target genes in prostate carcinoma cells identified by microarray analysis. J. Biol. Chem. 275: 38524-38531.

Szklarczyk, A. and Kaczmarek, L. 1997. Pharmacokinetics of antisense analogues in the central nervous system. Neurochem. Int. 31: $413-423$.

Thiel, G. and Cibelli, G. 2002. Regulation of life and death by the zinc finger transcription factor Egr-1. J. Cell. Physiol. 193: 287-292.

Thiel, G., Schoch, S., and Petersohn, D. 1994. Regulation of synapsin I gene expression by the zinc finger transcription factor zif268/egr-1. J. Biol. Chem. 269: 15294-15301.

Van Oekelen, D., Luyten, W.H., and Leysen, J.E. 2003. Ten years of antisense inhibition of brain G-protein-coupled receptor function. Brain Res. Rev. 42: 123-142.

Virolle, T., Krones-Herzig, A., Baron, V., De Gregorio, G., Adamson, E.D., and Mercola, D. 2003. Egr1 promotes growth and survival of prostate cancer cells: Identification of novel Egr1 target genes. J. Biol. Chem. 278: 11802-11810.

Wallace, K.J. and Rosen, J.B. 2000. Predator odor as an unconditioned fear stimulus in rats: Elicitation of freezing by trimethylthiazoline, a component of fox feces. Behav. Neurosci. 114: 912-922.

- 2001. Neurotoxic lesions of the lateral nucleus of the amygdala decrease conditioned fear, but not unconditioned fear of a predator odor: comparison to electrolytic lesions. J. Neurosci. 21: 3619-3627.

Received December 12, 2003; accepted in revised form June 29, 2004.

\section{Learning \& Memory}




\section{Errata}

Learning \& Memory 11: Issue 5 (2004)

The September Special Issue on Extinction contained the following errors:

Michael Davis, Professor of Psychiatry at Emory University, should have been acknowledged as the Guest Editor in the print edition of the Special Issue. Dr. Davis's expertise and assistance were invaluable to the success of the issue.

The article entitled "An egr-1 (zif268) Antisense Oligodeoxynucleotide Infused Into the Amygdala Disrupts Fear Conditioning" by Malkani et al. was mistakenly included in the Special Issue. It should have appeared in the November/December 2004 issue of Learning \& Memory. 


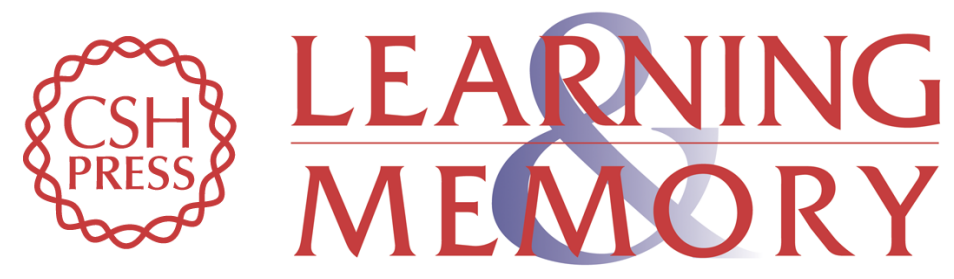

\section{An egr-1 (zif268) Antisense Oligodeoxynucleotide Infused Into the Amygdala Disrupts Fear Conditioning}

Seema Malkani, Karin J. Wallace, Melanie P. Donley, et al.

Learn. Mem. 2004, 11:

Access the most recent version at doi:10.1101//m.73104

Related Content Erratum for Volume 11, p. 617

Learn. Mem. November, 2004 11: 797

References This article cites 64 articles, 20 of which can be accessed free at:

http://learnmem.cshlp.org/content/11/5/617.full.html\#ref-list-1

Articles cited in:

http://learnmem.cshlp.org/content/11/5/617.full.html\#related-urls

License

Email Alerting Receive free email alerts when new articles cite this article - sign up in the box at the Service top right corner of the article or click here. 